\title{
Impacting Networked Technologies on Teaching Practices
}

\author{
Cutajar, Maria ${ }^{a}$ and Montebello, Matthew ${ }^{b}$ \\ ${ }^{a}$ Faculty of Education/Junior College (Computing \& IT), University of Malta, Malta, \\ ${ }^{\mathrm{b}}$ Faculty of Information and Communication Technology, University of Malta, Malta.
}

\begin{abstract}
Networked technologies are found permeating all work and life activities even in the education realm. Today's networked technologies are changing the way we interact within the online environment and amongst themselves. Networked technologies have unleashed a plethora of possibilities for educators to take advantage of by employing them as part of their teaching practices. In this paper are presented findings related to how academics are experiencing networked technologies for teaching and their relation to learning. A phenomenographic approach and subsequently a quantitative stance was employed to shed light on the nature and the current dynamic of such practices. This paper recounts the phenomenographic outcome, but it particularly attends to subsequent quantitative findings obtained from consideration of learning experiences against the phenomenographic map of variation in teaching experiences whereby an unexpected clustering trend was exposed. The outcomes of this exploratory research provide crucial and essential insights for higher education administrators and policy makers on how to regulate themselves with regards to the adoption of networked technologies within their institution.
\end{abstract}

Keywords: Networked Technologies; Phenomenography; Teaching; Higher Education; Web 2.0. 


\section{Introduction}

Networked technologies are found permeating all work and life activities even in the education realm. Policy-makers at international, national and institutional levels are encouraging educators to rise to the challenges of the networked era, embrace networked technologies in professional practice and in so doing exploit the potential of contemporary digital technologies for improving teaching and learning. Teachers are increasingly pressured to adapt their teaching practices to include networked technologies for teaching. In this paper the focus is particularly set on the role of networked technologies in the teaching methodologies of academics within higher education (HE) institutions, rather than teaching in general. The reason behind this delineation is in recognition that educators at the highest level of schooling need to take advantage and fruitfully employ these new technologies, to ensure that graduates are equipped with the required core transferrable skills as part of their generic competencies (Goodyear, 2002), today popularly referred to as 'twenty-first century skills'. These include "An extensive set of ... literacies (literacy, numeracy, citizenship, digital, and media); competencies (critical thinking, creativity, collaboration); and character qualities (curiosity, initiative, persistence, resilience, adaptability, leadership) that are believed to be critically important to success in the modern world" (HEA, 2018). If teaching academics aspire to instil such skills, they themselves require new skills to adapt to the dynamic nature of networked technologies and pedagogies that offer novel and potentially more effective teaching and learning experiences. This was amplified by the emergence of Web 2.0 (O'Reilly, 2005) technologies as current available networked technologies for learning that changed the way web pages and Internet applications generally are designed and used. According to Davies and Merchant (2009), Web 2.0 is a generation upgrade on the previous static World-Wide Web (WWW). It is comprised of dynamic technologies which endorse and propagate learner generated material, and moreover provide mechanisms that encourage and support interaction between Internet users more than ever before. To such extent, the authors claim that Web 2.0 technologies have the potential to enrich and transform the entire education process; as they point out four distinct ways of how learners, through Web 2.0 and today's networked technologies generally, experience learning (Cutajar, 2017a). Learners are also able to modify content itself as well as generate new material that can be appended to the content, and at the same time participate in the social activities that such technologies enable. These communal practices empower the learner (Bousaaid, et al., 2015) to actively produce, freely share, communicate and collaborate with other learners. Networked technologies as an integral part of the teaching and learning environment support the fostering of a learning eco-system that learners and tutors create and generate through blended and online activities. In view of these technological and social developments and their potential for teaching and learning, an exploratory investigation was taken up with a number of academics to analyse and document their experiences in engaging with networked 
technologies for teaching. The authors argue that such research is crucial to the continuous professional development of academics as well as to the development of HE teaching and learning which until recently was generally overlooked. This paper follows another research article (Cutajar, 2018) specifically reporting on the phenomenographic research outcome describing HE academics' experiencing of using networked technologies for teaching. This paper recounts this phenomenographic outcome, but it particularly attends to subsequent quantitative findings and the results obtained from consideration of participants' learning experiences against the phenomenographic map of variation in teaching experience obtained earlier whereby an unexpected clustering trend was exposed.

\section{Related Literature}

Web 2.0 technologies and evolving Internet applications have enabled a novel networked medium which educators and learners alike can benefit from. These technologies have "blurred the line between producers and consumers of content and shifted attention from access to information toward access to other people" (Brown \& Adler, 2008, p. 18). In this way networked technologies empower educators and learners to communicate and interact in new and natural ways that were not previously possible thereby creating a new educational medium that educators, even at a higher level, have to rethink and eventually require re-training and development (Montebello \& Camilleri, 2017). From a students' perspective, Cutajar (2017b) reports on variation in thinking about teachers and other students in a networked learning setting as in a pairwise tie expanding from the teacher as director of all learning and other students as separately persevering with their own studies, to the teacher as organiser and other students as direct learning contributors through their visible activity and interactivity, to the teacher as convener coming close to being a co-actor and other students as co-creators for learning. An active networked learning approach is proposed requiring learners to engage with each other, tutor and resources for learning. Networked learning is characterised by co-operation and collaboration within a learning group (McConnell, 2000). Goodyear et al. (2010) remark that "there is no point to networked learning if you do not value learning through co-operation, collaboration, dialog, and/or participation in a community" (p.2). The authors strongly believe that the use of networked technologies for teaching and learning offer innovative pedagogic prospects to educators in HE. This research was purposely aimed at exposing the different ways of discerning the use of such technologies for teaching. A fundamental premise giving direction to this research is that different ways of experiencing networked technologies for teaching are not right or wrong, but more, or less, elaborate ways of integrating contemporary digital technologies within professional practices (Cutajar, 2018). This premise links up to the notion that what academics see as most appropriate in their professional teaching substantially influences what they do in practice (Kirkwood \& Price, 
2014). Similar studies by Roberts (2003), Lameras, et al. (2012), and Shah (2014), investigated the employment of technologies within higher education, but focused on generic practices of how the web, learning technologies, and virtual learning environments are being productively used for teaching within the HE environment. In this research the focus is on the meaning-making and the related operationalisation of networked technologies in an effort to explore the academics' teaching experiences and the attainment of a current dynamic of variation in experiencing and how this relates to their learning.

\section{Research Methodology}

The empirical study was based on a purposive sample of 27 teaching academics within a HE institution. The sample of participants is demographically balanced in terms of academic entity of affiliation, discipline area of specialisation, tenure, status and gender. Data generation was carried out in the first quarter of 2016 using one-to-one semistructured interviews with consenting participants. Interviewees were invited to describe concrete examples of how they integrated networked technologies in their teaching, and to reflect on their motivations, intentions, student learning engagement and student learning benefit. Phenomenographic data analysis led to a map of variation in academics' experiencing of networked technologies for teaching. The phenomenographic map was subsequently used as a basis for charting a quantitative representation of academics' experiencing of networked technologies for teaching.

Phenomenography was employed because of its effective and compelling potential to set out different ways of experiencing a phenomenon of concern. Phenomenography originated from within the HE context (Richardson, 1999) to investigate students' learning engagement in reading activity. Limberg (2000) argues that this research approach is best performed through the compilation of interview data, bringing together as a single collective interviewees' descriptions of experience and conceptual thought. The combined accounts of the participants, rather than the individual interview transcripts are the unit object of phenomenographic data analysis for mapping out differences and similarities in ways of experiencing the concerned phenomenon; therefore the constitution of a structurally related set of distinct categories describing the person-phenomenon relationship. In doing phenomenographic analysis, one needs to focus on what is being said vis-a-vis the study phenomenon; for the case of this study, the meaning making and intertwined engagement to using networked technologies for teaching. The constituted categories expose a distinct way of perceiving, conceptualising and experiencing the study phenomenon (Marton \& Booth, 1997). Internally, each 'category of description' may incorporate further non-critical variation in describing a distinct way of relating to the phenomenon. The distinct categories are logically related forming a hierarchical inclusive 
structure technically referred to as the 'outcome space'. The outcome space is configured from the interview transcripts using an iterative process. The phenomenographic data analysis process for this study was comprised of 7 iterations each leading to the next set of categories of description. The first 4 iterations of the analysis were carried out with respect to the whole transcript data. Later iterations when the categories of description started to stabilise were done with reference to the relevant transcript excerpts highlighted in the previous rounds of data analysis. Qualitative data analysis (QDA) software conveniently served to organise, annotate and manage transcript data, and later facilitated retrieval of quotations. Åkerlind (2005) recommends an ongoing effort to support all claims by evidence from the collective of transcripts, and so an attempt to confirm or discredit each category until a final global agreement is achieved. Furthermore, Åkerlind (2005) points out that the category identification process requires counter-checking to ensure that the categories are communicatively valid, and that they jointly form the outcome space. A typical check requires another researcher, or researchers, to perform the identical process independently; and compare results hence engaging in a consultative dialogue to argue, defend and mutually scrutinise the conclusive decisions of each other. For the case of this research the phenomenographic analysis done by the first author was later validated by another independent phenomenographer. An electronic spreadsheet was subsequently employed to automate and complete the quantitative data analysis required for the later part of the research enterprise.

\section{Results and Discussion}

The resultant phenomenographic outcome space portrayed a distinctive variation made out of five (5) hierarchically inclusive categories of description. The resultant categories, from the least to the most elaborate ways of experiencing networked technologies for teaching are: Accumulating subject content; Motivating students to engage in learning; Building the teacher-student rapport; Modelling behaviour to inspire students; and Fostering a learning community. Cutajar (2018) provides a detailed account of these categories including elaborate descriptions of the distinct ways of experiencing using networked technologies for teaching at a higher education level. It is not the scope of this paper to develop a detailed discussion of this phenomenographic component of the research study, but notably this phenomenographic outcome advances the viewpoint that transmissive and participative teaching approaches are imperative teaching practices that are different and related. Furthermore, while the results confirm prior similar studies (such as those of Lameras, et al.(2012) and Shah(2014)), this description of variation distinctively exposes the use of networked technologies for projecting a caring attitude towards the learners. However, it also revealed the absent manifestation of the use of networked technologies for collaboration among academics as emerged from other similar studies. 
The representation of variation obtained from the earlier part of the study was used as a basis for relating academics' teaching experience to learning experience using networked technologies. A preliminary task was to explore the distribution of participants across the five (5) distinct ways of experiencing networked technologies for teaching as configured by the phenomenographic effort. This task was considered important in its capacity exposing the pattern of spread of the research sample.

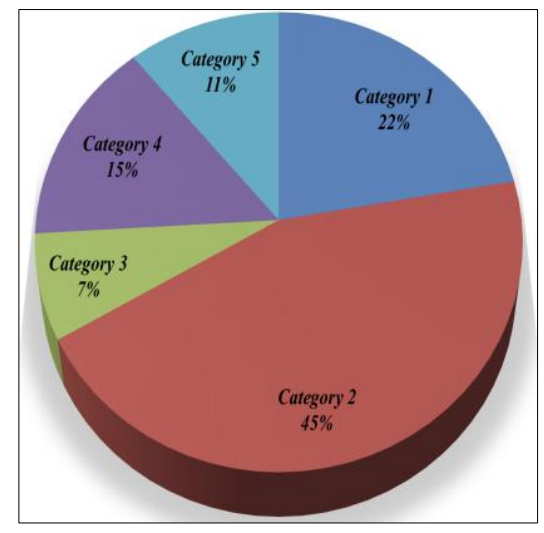

Figure 1 - Distribution of Transcripts

A representation of the obtained distribution is given by Figure 1. The different category percentages give an indication of how the transcript distributions were recorded. Approximately one fourth of the research participants $(25.92 \%)$ aligned to the more complex categories (Category 4 and Category 5) of using networked technologies for teaching focused on encouraging student participation and contribution to learning as well as fostering co-learning attitudes (beyond any transmission effort). The majority of the participants aligned mostly to the less elaborate categories with $22.22 \%$ in Category 1 focusing on passing on (factual) disciplinary knowledge, $44.44 \%$ in Category 2 focusing on getting across to students the understanding of disciplinary knowledge, while $7.41 \%$ in Category 3 focusing on conveying a caring attitude using networked technologies. At large, $74.07 \%$ of the participants aligned to a category representing a transmissive teaching attitude using networked technologies (Categories 1, 2 and 3) as compared to the $25.93 \%$ of the participants aligning to categories over and above advancing participative attitudes (Categories 4 and 5). 


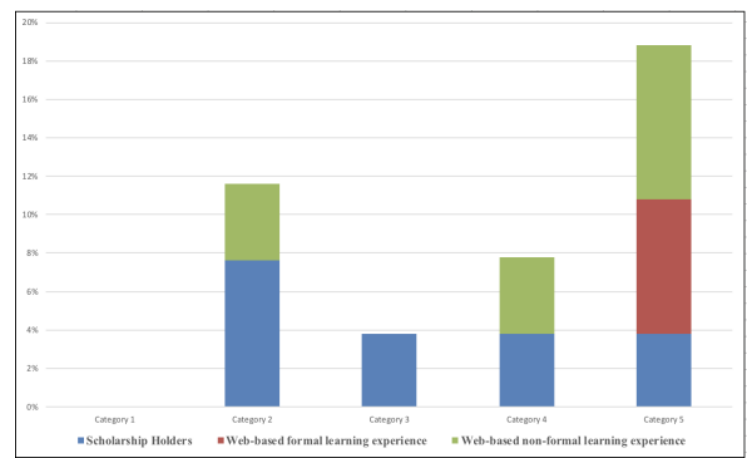

Figure 2 - Relation between Teaching \& Learning

In relation to online learning, $19 \%$ of the participants were scholarship holders of an online teaching certification course that encouraged the adoption of networked technologies. Another $7 \%$ of the participants referred to their web-based formal learning experiences during the individual interviews. Furthermore, $15 \%$ of the participants (one of whom was also a scholarship holder) talked about non-formal learning experiences (such as synchronous meetings with supervisors when reading post-graduate studies; reading a massive open online course (MOOC); and so on). A good number of participants also described informal web-based learning activities such as watching recordings shared on video-sharing websites such as YouTube, and listening in on webinars which they came across. Figure 2 presents the spread of participants' online learning experience in relation to the phenomenographic spectrum of expanding awareness generated from the first part of this explorative study. Noteworthy is the finding that the participants who experienced webbased online learning emerged as aligning to the more elaborate ways of seeing online teaching - the red coloured section of the rightmost column. This finding is remarkable in realisation that these participants are not scholarship holders (reading the distance learning course on online teaching) but claimed positive web-based collaborative learning experiences.

\section{Concluding Remarks}

In this paper there were shared some of the results of a research study investigating teaching academics' experiences of using networked technologies within a HE institution. The core significance of the qualitative part of the research is that the variation in academics' experiences using networked technologies for teaching is not to be considered in terms of transmissive and participative binaries, but more constructively as significant aspects of the same teaching approach. The quantitative research findings presented by this paper underscore the pressing need to support academics at the academy to develop as $21 \mathrm{st}$ 
century educators and their development of teaching using networked technologies. They signal the need for further research to explore the conditions whereby the experience of learning using networked technologies can be truly claimed to incite the development of teaching using networked technologies. But in the meantime, constructive efforts responding to the challenges implicated by the results of this study would build and expand on current practices and encourage self-initiated effort so as to positively develop teaching at HE levels in what we are experiencing as the networked era.

\section{References}

Åkerlind, G. S. (2005). Variation and commonality in phenomenographic research methods. Higher Education Research and Development, 321-334.

Brown, J. S., \& Adler, R. P. (2008). Minds on fire: Open Education, the Long Tail, and Learning 2.0. Educase Review, 43(1), 17-32.

Cutajar, M. (2017a). The student experience of learning using networked technologies: an emergent progression of expanding awareness. Technology, Pedagogy and Education, 26(4), 485-499. doi:10.1080/1475939x.2017.1327451

Cutajar, M. (2017b). Students' perceptions of others in a networked learning environment. In Networked Learning: Looking Back - Moving Forward. London: Springer.

Cutajar, M. (2018). Teachers' experiences using networked technologies for teaching. Paper presented at the Eleventh International Conference on Networked Learning, Zagreb, Croatia.

Davies, J., \& Merchant, G. (2009). Web 2.0 for Schools - Learning and Social Participation. New York: Peter Lang.

Goodyear, P. (2002). Psychological Foundations of Networked Learning. In Networked Learning: Perspectives and Issues. London: Springer.

Goodyear, P., Banks, S., Hodgson, V., \& McConnell, D. (2010). Advances in research on Networked Learning. Dordrecht: Kluwer Academic Publishers.

HEA (Producer). (2018, Jan 25). 21st Century Skills. Higher Education Academy. Retrieved from https:/www.heacademy.ac.uk/knowledge-hub/21st-century-skills

Kirkwood, A., \& Price, L. (2014). Technology-enhanced learning and teaching in higher education: what is 'enhanced' and how do we know? A critical literature review. Learning, Media and Technology, 39(1), 6-36.

Lameras, P., Levy, P., Paraskakis, I., \& Webber, S. (2012). Blended university teaching using virtual learning environments: conceptions and approaches. Instructional Science, 40(1), 141-157.

Li, L., Steckelberg, A. L., \& Srinivasan, S. (2008). Utilizing peer interactions to promote learning through a computer-assisted peer assessment system. Canadian Journal of Learning and Technology, 34(2).

Limberg, L. (2000). Phenomenography: a relationship approach to research on information needs, seeking and use. The New Review of Information Behavior Research, 51-67. 
Marton, F., \& Booth, S. (1997). Learning and awareness. Mahwah, NJ: Lawrence Earlbaum Assoc.

McConnell, D. (2000). Implementing Computer Supported Cooperative Learning (2nd ed.). London, UK: Kogan Page.

Montebello, M. \& Camilleri, V. (2017) Social Media in Higher Education. In: Proceedings of the 3rd International Conference on Learning and Teaching, ICLT2017. Jeju Island, South Korea.

Richardson, J. (1999). The concepts and methods of phenomenographic research. Review of Educational Research, 53-82.

Roberts, G. (2003). Teaching using the web: conceptions and approaches from a phenomenographic perspective. Instructional Science, 31(1/2), 127-150.

Safran, S. (2010). Social Media in Education. Graz, Austria: Graz University of Technology.

Shah, U. (2014). Teacher's Use of Learning Technology in a South Asian Context. In The Design, Experience and Practice of Networked Learning. Switzerland: Springer International Publishing. 